\title{
Drought assessment using a multivariate drought index in the Huaihe River basin of Eastern China
}

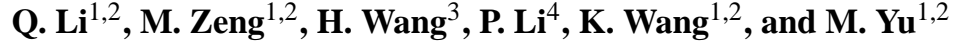 \\ ${ }^{1}$ College of Hydrology and Water Resources, Hohai University, Nanjing, China \\ ${ }^{2}$ Center for International River Research, Hohai University, Nanjing, China \\ ${ }^{3}$ Henan Hydrology and Water Resources Survey Bureau, Zhengzhou, China \\ ${ }^{4}$ Xinyang Hydrology and Water Resources Survey Bureau, Xinyang, China
}

Correspondence to: Q. Li (li_qiongfang @ hotmail.com)

Received: 28 April 2015 - Accepted: 28 April 2015 - Published: 11 June 2015

\begin{abstract}
The Huaihe River Basin having China's highest population density (662 persons per $\mathrm{km}^{2}$ ) lies in a transition zone between the climates of North and South China, and is thus prone to drought. Therefore, the paper aims to develop an appropriate drought assessment approach for drought assessment in the Huaihe River basin, China. Based on the Principal Component Analysis of precipitation, evapotranspiration, soil moisture and runoff, the three latter variables of which were obtained by use of the Xin' anjiang model, a new multivariate drought index (MDI) was formulated, and its thresholds were determined by use of cumulative distribution function. The MDI, the Standardized Precipitation Index (SPI) and the self-calibrating Palmer Drought Severity Index (scPDSI) time series on a monthly scale were computed and compared during 1988, 1999/2000 and 2001 drought events. The results show that the MDI exhibited certain advantages over the sc-PDSI and the SPI in monitoring drought evolution. The MDI formulated by this paper could provide a scientific basis for drought mitigation and management, and references for drought assessment elsewhere in China.
\end{abstract}

\section{Introduction}

Droughts are the costliest one of all natural disasters over the world, and often lead to significant societal, economic, and ecologic impacts (Farahmand and Aghakouchak, 2014). Droughts usually affect more people than any other form of natural hazards (Wilhite, 2000) and might have more serious influence at a global scale with the world's population increasing (McLeman, 2010) and the frequency and intensity of droughts being likely to change more rapidly under the impacts of anthropogenic global warming progresses (Dai et al., 2004; Dai, 2011). Therefore, drought assessment is a hot topic among hydrologists and meteorologists, and attracted a world-wide attention (Yu et al., 2014; Jain et al., 2010; Todisco et al., 2013; Sohrabiz et al., 2013; Giraldo and García, 2012; Li et al., 2015). Due to China's special climatological and topographical features, China is one of the countries frequently suffering drought hazards in the world, and both drought frequency and intensity have demonstrated an obvious rising trend with climate change (Yu et al., 2014). Thus, many researchers in China made contributions to drought monitoring and assessment (Li et al., 2015; Qian et al., 2011; Li et al., 2012; Wang et al., 2012).

Currently, there exist a number of drought indices that have been used to represent different types of droughts including meteorological or climatological, agricultural and hydrological droughts. Most of drought indices based on one or two specific hydro-meteorological variables can only monitor one specific physical form of drought: hydrological, meteorological, or agricultural (Rajsekhar et al., 2014; Heim, 2002). In recent years, some multivariate drought indices that consider a wide range of hydrological, agricultural, meteorological variables has been proposed and applied ( $\mathrm{Li}$ et al., 2015; Rajsekhar et al., 2014; Svoboda, 2002; Brown et al., 2008; Hao and AghaKouchak, 2013; Zhang and Jia, 2013; Mu et al., 2013; Keyantash and Dracup, 2004). However, precise physical quantification of drought intensity by these indices is still a tough task (Keyantash and Dracup, 2004). The aim of this paper is to develop a multivariate drought index 
(MDI) by incorporating multiple variables to better depict drought evolution in the upper Huaihe River basin, China. The MDI could comprehensively consider all physical forms of drought - meteorological, hydrological and agricultural (as defined in Heim, 2002) - through selection of multiple hydrometeorological variables, important to each physical form of drought and easily obtained by observation or model simulation.

\section{Data and methods}

\subsection{Methods}

To develop an appropriate drought index for Eastern China, the Huaihe River basin was selected as a case study site. A monthly time series of the MDI was computed through application of the Principal Component Analysis (PCA) to monthly evapotranspiration, soil moisture content, runoff and precipitation. The Xin'anjiang model (Zhao, 1992) was applied to simulate daily evapotranspiration, soil moisture and runoff processes in the Huaihe River basin according to its rainfall-runoff mechanism (saturation excess runoff). The Xin'anjiang model was run in each grid with a size of $1 \mathrm{~km} \times 1 \mathrm{~km}$ to gain its daily $P, W, E$ and $R$ on a daily basis during 1988-2002. The daily time series of areal mean values of $P, W, E$ and $R$ were obtained by averaging their daily values from all grids, and their monthly time series were acquired by summing up their daily values on a monthly scale. The MDI thresholds were determined by cumulative distribution function and its applicability was examined by comparison with the SPI (McKee et al., 1993) and the sc-PDSI (Wells et al., 2004) in assessing 1988, 1999/2000 and 2001 drought events.

\subsection{Data collection and processing}

The topographic and hydro-meteorological data were collected for each grid of $1 \mathrm{~km} \times 1 \mathrm{~km}$ in the Huaihe River basin. The digital elevation model (DEM) data was downloaded from the NOAA National Geophysical Data Center (NGDC), and the Archydro tool was used in the delineation of the boundaries of the study area. The daily 1988-2005 time series of rainfall from sixty-three rainfall gauges in the study area, and discharge and evaporation from the Xixian hydrology station were collected for daily simulation. The homogeneity and reliability of the data have been checked and firmly controlled by the Huaihe River Water Resources Commission and China Meteorological Administration. The inverse distance weighting interpolation method was employed to spatially interpolate meteorological data for every grid.

\section{Study area}

The Huaihe river basin is one of seven major river basins in China, and is located between the Yellow and Yangtze

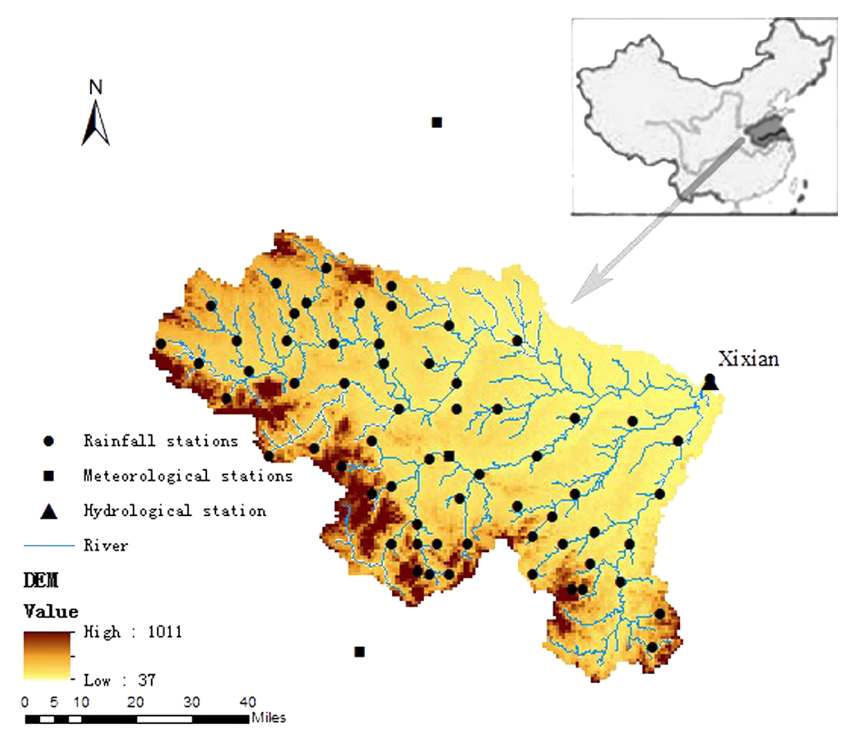

Figure 1. The location of Xixian Catchment.

Rivers, with an area of $270000 \mathrm{~km}^{2}$. Like them, the Huaihe flows from west to east, and is situated between latitudes $31^{\circ} 0^{\prime} 0$ and $35^{\circ} 0^{\prime} 0 \mathrm{~N}$ and between longitudes $112^{\circ} 0^{\prime} 0$ and $121^{\circ} 0^{\prime} 0 \mathrm{E}$. This region has China's highest population density (662 persons per $\mathrm{km}^{2}$ ) and is thus of great socioeconomic importance. Climatologically, it lies in the warm temperature semi-humid monsoon region, which is a transition zone between the climates of North and South China, and is thus prone to drought. This paper selected the upper Huaihe River above the Xixian hydrologic station as a case study site (Fig. 1). The Xixian subbasin has a catchment of $1.019 \times 104 \mathrm{~km}^{2}$ with an average annual precipitation of $1145 \mathrm{~mm}$, an average annual runoff of $371 \mathrm{~mm}$ and an average annual pan evaporation of $922 \mathrm{~mm}$. The intra-annual distribution of precipitation is very uneven with precipitation mainly occurring in the period from mid- May to midOctober, and the inter-annual variation of precipitation is also significant. These features in precipitation may be a major factor leading to drought.

\section{MDI formulation and application}

\subsection{Xin'anjiang model application}

The Xin'anjiang model (Zhao, 1992) is a rainfall-runoff, distributed, basin model for use in humid and semi-humid regions, and has been widely applied in China. The model consists of three modules: evaporation, runoff and flow concentration. The evapotranspiration component is represented by a model of three soil layers. Runoff production occurs on repletion of storage to capacity values which are assumed to be distributed throughout the basin. The runoff was separated into surface, interflow and groundwater components based Horton's concept of infiltration and the concept of hillslope 
Table 1. Eigenvalues and eigenvectors used for the computation of monthly MDI values.

\begin{tabular}{lrrrrrr|rrrrr}
\hline \multirow{2}{*}{ Month } & $\lambda_{1}$ & $\lambda_{2}$ & \multicolumn{6}{c}{$e_{1}$} & \multicolumn{4}{c}{$e_{2}$} \\
\cline { 4 - 11 } & & & $e_{1 \mathrm{p}}$ & $e_{1 \mathrm{e}}$ & $e_{1 \mathrm{r}}$ & $e_{1 \mathrm{w}}$ & $e_{2 \mathrm{p}}$ & $e_{2 \mathrm{e}}$ & $e_{2 \mathrm{r}}$ & $e_{2 \mathrm{w}}$ \\
\hline January & 2.06 & 1.01 & 0.73 & 0.90 & -0.07 & 0.85 & 0.15 & -0.09 & 0.99 & 0.05 \\
February & 2.50 & 1.07 & 0.47 & 0.60 & 0.33 & 0.56 & -0.58 & -0.17 & 0.77 & 0.21 \\
March & 2.30 & 1.13 & 0.56 & 0.60 & -0.09 & 0.56 & 0.36 & -0.02 & 0.91 & -0.20 \\
April & 2.18 & 1.04 & 0.53 & 0.61 & -0.28 & 0.52 & 0.46 & 0.22 & 0.81 & -0.29 \\
May & 2.28 & 1.02 & 0.56 & 0.62 & -0.03 & 0.55 & -0.04 & -0.07 & 0.98 & 0.16 \\
June & 2.80 & 0.70 & 0.52 & 0.55 & -0.43 & 0.50 & -0.20 & 0.32 & 0.77 & 0.51 \\
July & 3.04 & 0.69 & 0.53 & 0.54 & -0.45 & 0.47 & -0.24 & 3.65 & 0.69 & 0.63 \\
August & 2.83 & 0.86 & 0.56 & 0.55 & -0.34 & 0.53 & -0.11 & 0.26 & 0.87 & 0.40 \\
September & 2.49 & 1.19 & 0.50 & 0.60 & 0.18 & 0.59 & -0.48 & -0.05 & 0.86 & 0.19 \\
October & 2.26 & 1.04 & 0.56 & 0.63 & 0.18 & 0.51 & 0.14 & -0.06 & 0.90 & -0.40 \\
November & 2.45 & 0.89 & 0.55 & 0.54 & -0.29 & 0.57 & 0.07 & 0.33 & 0.94 & 0.10 \\
December & 1.62 & 1.33 & 0.62 & 0.56 & -0.36 & 0.41 & 0.30 & 0.47 & 0.63 & -0.54 \\
\hline
\end{tabular}

Note: $e_{1}$ and $e_{2}$ are the eigenvectors associated with PC1 and PC2 respectively; $e_{1 \mathrm{p}}, e_{1 \mathrm{r}}, e_{1 \mathrm{e}}$ and $e_{1 \mathrm{w}}$ are the coefficients of precipitation, runoff, evapotranspiration and soil moisture content in $e_{1}$, and $e_{2 \mathrm{p}}, e_{2 \mathrm{e}}, e_{2 \mathrm{r}}$ and $e_{2 \mathrm{w}}$ are the coefficients of precipitation, runoff, evapotranspiration and relative soil moisture in $e_{2}$.

hydrology. The concentration of surface runoff, interflow and groundwater on the hillslope to the nearest river channel is represented by a linear-reservoir routing technique respectively. The concentration of flow to the outlet of the basin in the channel system is represented by Muskingum routing. There are fifteen parameters in all, of which the model is particularly sensitive to six. In this study, the Xin' anjiang model was used to reconstruct daily water balance components (soil moisture content, evaporation and runoff) at a spatial resolution of $1 \mathrm{~km}$.

To run the Xin'anjiang model, four types of parameters, i.e. evapotranspirition, runoff production, runoff separation, and runoff concentration parameters, need to be determined. The Xin'anjiang model was calibrated by use of daily data from 1 January 1988 to 31 December 1998, and validated from 1 January 1999 to 31 December 2002. The performance of the Xin'anjiang model was evaluated by the following indicators:

Relative Error $(\mathrm{RE}): \mathrm{RE}=\left(R_{\mathrm{c}}-R_{\mathrm{O}}\right) / R_{\mathrm{o}}$

Modeling Efficiency (EF) : EF $=1-\frac{\sum_{i=1}^{n}\left(Q_{\mathrm{c}}-Q_{\mathrm{o}}\right)^{2}}{\sum_{i=1}^{n}\left(Q_{\mathrm{o}}-\bar{Q}\right)^{2}}$

where $R_{\mathrm{C}}$ and $R_{\mathrm{O}}$ are the computed and the observed annual runoff respectively $(\mathrm{mm})$, which were calculated respectively on the basis of daily computed and observed runoff $(\mathrm{mm}) ; n$ is the number of days in a each year, $Q_{\mathrm{c}}$ and $Q_{\mathrm{o}}$ are the computed and the observed daily discharge respectively on day $i\left(\mathrm{~m}^{3} \mathrm{~s}^{-1}\right), \bar{Q}$ is the average of observed daily discharge $\left(\mathrm{m}^{3} \mathrm{~s}^{-1}\right)$.

\subsection{MDI creation and application}

\subsubsection{Construction of the MDI}

The formulation of the MDI should fully consider the impacts of water budget which is made up of precipitation $(P)$, evapotranspiration $(E)$, soil moisture content $(W)$, runoff $(R)$, groundwater storage $(G)$, snow water content $(S)$ and surface water storage on drought process and intensity. In this study, surface water storage, snow water content and groundwater storage were not taken into account, and soil moisture content was replaced by relative soil moisture (RW) (Li et al., 2015). Thus, the MDI was formulated on the basis of the Principal component analysis (PCA) (Cattell, 1952) of $P, E$, $R$ and RW. To eliminate the influence of the dimensions of the variables $(P, E$, RW and $R)$, they all were standardized. Since the monthly distributions of precipitation, evapotranspiration and runoff were uneven, the MDI was formulated for each month respectively. The MDI was formulated as a linear combination of the first and the second principal components (PC1 and $\mathrm{PC} 2)$ :

$\mathrm{MDI}_{i, k}=\frac{\lambda_{1, k}}{\lambda_{1, k}+\lambda_{2, k}} Z_{1, i, k}+\frac{\lambda_{2, k}}{\lambda_{1, k}+\lambda_{2, k}} Z_{2, i, k}$

where $\mathrm{MDI}_{i, k}$ is the monthly MDI value in month $k$ of year $i, Z_{1, i, k}$ and $Z_{2, i, k}$ are the first and the second $\mathrm{PC}$ in month $k$ of year $i, \lambda_{1, k}$ and $\lambda_{2, k}$ are the first and the second PC's eigenvalue of month $k$.

According to the mathematical methods described above, the eigenvectors and eigenvalues corresponding respectively to PC1 and PC2 were formulated and showed in Table 1.

\subsubsection{Drought Intensity Scale for the MDI}

The MDI thresholds were determined probabilistically on the basis of the MDI percentiles from empirical cumulative dis- 
Table 2. The dryness thresholds of the MDI, the sc-PDSI and the SPI.

\begin{tabular}{lrrr}
\hline \multirow{2}{*}{ Magnitude } & \multicolumn{3}{c}{ Range } \\
\cline { 2 - 4 } & MDI & sc-PDSI & SPI \\
\hline normal & $(1.11,+\infty)$ & $(-1.0,+\infty)$ & $(-0.5,+\infty)$ \\
near-normal & $(-1.15,1.11)$ & $(-2.0,-1.0)$ & $(-1,-0.5)$ \\
moderate & $(-1.43,-1.15)$ & $(-3.0,-2.0)$ & $(-1.5,-1)$ \\
severe & $(-1.88,-1.43)$ & $(-4.0,-3.0)$ & $(-2.0,-1.5)$ \\
extreme & $(-\infty,-1.88)$ & $(-\infty,-4.0)$ & $(-\infty,-2.0)$ \\
\hline
\end{tabular}

tribution function (ECDF) (Hao and AghaKouchak, 2013). Since the SPI thresholds are quantified by ECDF and it performs well in drought assessment of the Huaihe river basin, where precipitation is a key variable controlling drought occurrence and evolution, the MDI percentiles were selected as what SPI adopted (McKee et al., 1993), i.e. the 2nd, 7th, 16th and 84th percentiles, and the MDI threshold ranges were determined as following: -1.88 and less, extreme drought; -1.88 to -1.43 , severe drought; -1.43 to -1.15 , moderate drought; -1.15 to 1.11 , near-normal; 1.11 and more, normal (see Table 2).

\subsubsection{MDI application}

The historical droughts that occurred in Huaihe River basin including 1988, 1999/2000 and 2001 drought events were chosen to test the applicability of the newly proposed MDI based on the following facts: these droughts were among the most severe ones; they were well recorded, including the damage and duration. Furthermore, the sc-PDSI and the SPI on a monthly scale were also employed to assess these droughts and the suitability of the MDI, the sc-PDSI and the SPI was evaluated.

\section{Results and discussion}

\subsection{The Xin'anjiang model simulation}

Table 3 indicated that the Xin' anjiang model performed well with an average ME value, being 0.71 and 0.65 for calibration and validation periods respectively and all RE values being within $\pm 10 \%$ for both calibration and validation periods. To save space, only simulated hydrographs for the years of 1988 (calibration) and 2000 (validation) were presented (Fig. 2). It can be expected that the average ME value would increase with the simulation time scale from a daily scale to a monthly scale. According to the hydrological forecasting standards issued by the Ministry of Water Resources, China, it can be concluded that the simulated streamflow is of sufficient accuracy and the Xin' anjiang model is applicable to the Huaihe River basin. According to model equifinality (Beven, 2006), it can be assumed that the simulated evapotranspiration, runoff and soil water content by the Xin'anjiang model
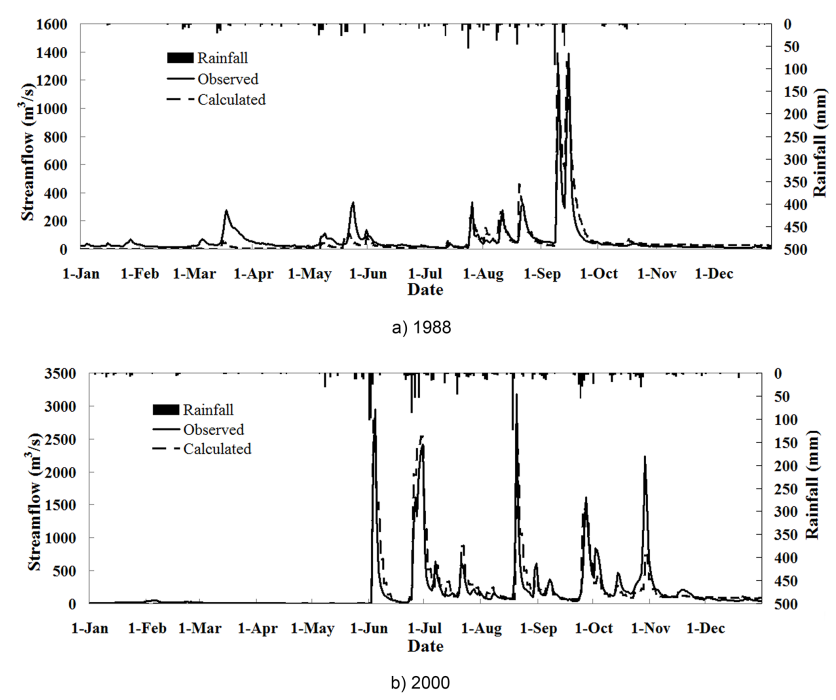

Figure 2. Simulated and Observed hydrographs for the years of 1988 and 2000.

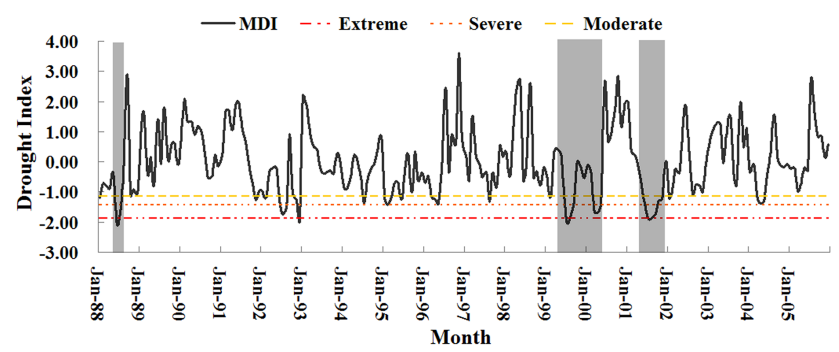

Figure 3. Monthly time series of MDI for Huaihe River basin.

also have sufficient accuracy due to streamflow being an integrator of these processes, and therefore they are acceptable in the formulation of the MDI.

\subsection{Drought assessment with the MDI, the Sc-PDSI and the SPI}

The monthly time series of the MDI for the study area is shown in Fig. 3. The grey shaded areas in Fig. 3 well indicated the durations of the historical droughts that occurred in the Huaihe River basin in 1988, 1999 to 2000 and 2001. Figure 3 revealed clearly that the monthly MDI time series successfully demonstrated these historical droughts with its lower values falling within the grey shaded areas. The scPDSI and the SPI on a monthly scale during the historical droughts were computed and compared with the MDI as below.

\subsubsection{Drought}

The first shaded area in Fig. 3 corresponds to the 1988 drought. As the historical records showed, the 1988 drought has been one of the worst droughts since 1949 in Huaihe 
Table 3. Daily simulation performance of the Xin'anjiang Model during 1988-2005.

\begin{tabular}{lrrrrrr}
\hline Application & Year & $P(\mathrm{~mm})$ & $R_{\mathrm{O}}(\mathrm{mm})$ & $R_{\mathrm{c}}(\mathrm{mm})$ & $\mathrm{RE}(\%)$ & $\mathrm{ME}$ \\
\hline calibration & 1988 & 787.6 & 193.8 & 177.4 & -8.4 & 0.717 \\
& 1989 & 1153.0 & 475.1 & 472.5 & -0.6 & 0.791 \\
& 1990 & 877.6 & 295.9 & 298.5 & 0.9 & 0.498 \\
& 1991 & 1197.7 & 609.8 & 554.7 & -9.0 & 0.800 \\
& 1992 & 744.2 & 149.8 & 138.2 & -7.8 & 0.560 \\
& 1993 & 840.5 & 224.5 & 229.1 & 2.1 & 0.584 \\
& 1994 & 849.6 & 179.0 & 163.9 & -8.4 & 0.662 \\
& 1995 & 881.2 & 214.8 & 199.3 & -7.2 & 0.806 \\
& 1996 & 1141.5 & 521.0 & 489.5 & -6.0 & 0.783 \\
& 1997 & 782.3 & 226.0 & 225.1 & -0.4 & 0.769 \\
& 1998 & 1166.6 & 616.4 & 564.7 & -8.4 & 0.857 \\
\hline \multirow{6}{*}{ validation } & 1999 & 573.8 & 80.3 & 76.5 & -4.8 & 0.710 \\
& 2000 & 1328.0 & 578.4 & 522.0 & -9.7 & 0.734 \\
& 2001 & 456.6 & 104.6 & 107.2 & 2.5 & 0.363 \\
& 2002 & 1108.1 & 348.2 & 316.1 & -9.2 & 0.803 \\
\hline
\end{tabular}

Table 4. The dryness assessment of the 1988 drought by MDI, scPDSI and SPI.

\begin{tabular}{llll}
\hline Month & \multicolumn{3}{c}{ Magnitude } \\
\cline { 2 - 4 } & MDI & sc-PDSI & SPI \\
\hline Jan 1988 & moderate drought & normal & near-normal \\
Feb 1988 & near-normal & normal & moderate drought \\
Mar 1988 & near-normal & normal & normal \\
Apr 1988 & near-normal & normal & normal \\
May 1988 & near-normal & normal & normal \\
Jun 1988 & extreme drought & near-normal & moderate drought \\
Jul 1988 & severe drought & normal & near-normal \\
Aug 1988 & near-normal & normal & near-normal \\
Sep 1988 & normal & normal & normal \\
Oct 1988 & near-normal & normal & normal \\
Nov 1988 & near-normal & near-normal & normal \\
Dec 1988 & near-normal & near-normal & moderate drought \\
\hline
\end{tabular}

Note: The duration with bold is the recorded drought period.

River basin. The drought started from May and ended in August, and the rainfall in these months decreased significantly compared with their long-term mean rainfall, particularly in June, reducing by more than $60 \%$. Moreover, some small branches were drying up in June and July. The dryness assessments by these three drought indices were given in Table 4. Table 4 demonstrated that the MDI best reflected the drought evolution among these three indices. The severity of the drought assessed by the SPI was milder than the actual situation. The sc-PDSI almost failed to identify this serious drought. The MDI also identified the start and the end of the 1988 drought.

\subsubsection{9/2000 Drought}

According to the records of history, the 1999/2000 drought (corresponding to the second shaded areas in Fig. 3) in the
Table 5. The dryness assessment of the 1999/2000 drought by MDI, sc-PDSI and SPI.

\begin{tabular}{llll}
\hline Months & \multicolumn{3}{c}{ Magnitude } \\
\cline { 2 - 4 } & MDI & sc-PDSI & SPI \\
\hline Jun 1999 & near-normal & normal & near-normal \\
Jul 1999 & extreme & near-normal & severe \\
Aug 1999 & severe & near-normal & severe \\
Sep 1999 & moderate & moderate & extreme \\
Oct 1999 & near-normal & near-normal & near-normal \\
Nov 1999 & near-normal & near-normal & normal \\
Dec 1999 & near-normal & moderate & normal \\
Jan 2000 & near-normal & near-normal & normal \\
Feb 2000 & near-normal & near-normal & near-normal \\
Mar 2000 & severe & moderate & moderate \\
Apr 2000 & severe & severe & extreme \\
May 2000 & severe & severe & severe \\
Jun 2000 & normal & normal & normal \\
\hline
\end{tabular}

Note: The duration with bold is the recorded drought period.

Huaihe River basin took place in June to September of 1999 and March to June of 2000. During the drought, an evident reduction in monthly rainfalls occurred, being 50 to $80 \%$ of their mean annual values, while the monthly evapotransporation and air temperature were above their mean annual values respectively. All these factors worked together to aggravate the drought during the spring of 2000, and as a result, a large area in the Huaihe river basin suffered the drought, and a number of small- and medium-sized rivers dried up. The drought dryness assessment by these indices was illustrated in Table 5. From Table 5, it can be seen that the drought severity monitored by the sc-PDSI was much milder than that by the MDI and the SPI, and the response of the sc-PDSI to the start of the 1999/2000 drought seriously delayed and al- 
Table 6. The dryness assessment of the 2001 drought by MDI, scPDSI and SPI.

\begin{tabular}{llll}
\hline Month & \multicolumn{3}{c}{ Magnitude } \\
\cline { 2 - 4 } & MDI & sc-PDSI & SPI \\
\hline Jan 2001 & normal & normal & normal \\
Feb 2001 & near-normal & normal & normal \\
Mar 2001 & near-normal & normal & normal \\
Apr 2001 & near-normal & normal & moderate \\
May 2001 & near-normal & normal & extreme \\
Jun 2001 & severe & normal & extreme \\
Jul 2001 & extreme & normal & extreme \\
Aug 2001 & severe & normal & severe \\
Sep 2001 & severe & normal & extreme \\
Oct 2001 & moderate & near-normal & severe \\
Nov 2001 & moderate & near-normal & moderate \\
Dec 2001 & near-normal & normal & normal \\
\hline
\end{tabular}

Note: The duration with bold is the recorded drought period.

most failed to identify the drought during June to September of 1999. The SPI performed better in the monitoring of the drought than the sc-PDSI, but the difference between the picture depicted by the SPI and the actual situation still existed. The drought severity identified by the MDI during the periods of June to September of 1999 and March to June of 2000 was well consistent with the historical records. Thus, the MDI performed best in terms of both drought severity and drought evolution.

\subsubsection{Drought}

The 2001 drought (corresponding to the third shaded areas in Fig. 3) in the Huaihe River basin was the worst recorded drought since 1949, starting in June and ending in November. An obvious reduction in rainfall occurred during April to July with its amount being about $58 \%$ of the normal value, and a number of small- and medium-sized rivers dried up. Table 6 presented the drought dryness assessment by these three indices. From Table 6, it can be clearly seen that the sc-PDSI almost failed to monitor the drought. Both of the MDI and the SPI monitored the drought evolution. However, the drought period depicted by the SPI was longer than the actual one. Since the SPI is sensitive only to rainfall, the dryness assessment by the SPI may be more serious than the actual situation with a reduction of rainfall in April and May. Compared with the sc-PDSI and the SPI, the MDI demonstrated good agreement with the actual drought evolution. Both the MDI and the SPI detected the end of the drought.

The above analysis indicated that the sc-PDSI performed not good enough for drought dryness assessment in the Huaihe River basin due to its inherent disadvantages: the assumption of the PDSI that runoff cannot occur unless soil moisture is at field capacity being not always true; and the PDSI being difficult to account for the lag between mois- ture surplus and streamflow with a rather crude water balance model being used in the PDSI (Alley, 1984). Both the SPI and the MDI can be used to monitor the droughts in the Huhaihe River basin, but the MDI performed better in terms of drought duration and severity due to drought occurrence and evolution being not only closely associated with precipitation but also other different variables, such as evapotranspiration, soil moisture status, and streamflow.

\section{Conclusions}

The drought dryness assessment in terms of the drought duration and magnitude for the three typical droughts in historical records (i.e. the 1988 drought, the 1999/2000 drought and the 2001 drought) was carried out by drought indices of the MDI, the sc-PDSI and the SPI and compared. The results revealed: The MDI and the SPI were applicable in the Huaihe river basin with the MDI performing best. The scPDSI failed to monitor the three typical droughts. The MDI provides a simple approach to evaluate droughts by comprehensively considering multiple hydrological variables about the drought including precipitation, evapotranspiration, soil moisture and runoff which are easily obtained by observation and model simulation. Moreover, the MDI has widely feasibility that factors used in the MDI computation depend on the local climate and the weight in each variable is determined by the hydrological conditions in the study area.

Acknowledgements. Financial support is gratefully acknowledged from the National Science Foundation Commission under Grant No. 41171220, China, and the "111" Project under Grant B08048.

\section{References}

Alley, W. M.: The Palmer Drought Severity Index: Limitations and Assumptions, J. Clim. Appl. Meteor., 23, 1100-1109, 1984.

Beven, K.: A manifesto for the equifinality thesis, J. Hydrol., 320, 18-36, 2006.

Brown, J. F., Wardlow, B. D., Tadesse, T., Hayes, M. J., and Reed, B. C.: The Vegetation Drought Response Index (VegDRI): A new integrated approach for monitoring drought stress in vegetation, Gisci. Remote. Sens., 45, 16-46, 2008.

Cattell, R. B.: Factor Analysis: An Introduction and Manual for the Psychologist and Social Scientist, 462 pp., Greenport Press, Westport, Conn, 1952.

Dai, A.: Drought under global warming: a review, Wiley, Interdisc. Rev. Clim. Change, 2, 45-65, 2011.

Dai, A., Trenberth, K. E., and Qian, T.: A Global Dataset of Palmer Drought Severity Index for 1870-2002: Relationship with Soil Moisture and Effects of Surface Warming, J. Hydrometeorol., 5, 1117-1130, doi:10.1175/JHM-386.1, 2004.

Farahmand, A. and AghaKouchak, A.: A generalized framework for deriving nonparametric standardized 
drought indicators, Adv. Water Resour., 76, 140-145, doi:10.1016/j.advwatres.2014.11.012, 2014.

Giraldo, O. J. D. and García, G. S. G.: Non-stationary analysis of dry spells in monsoon season of Senegal River Basin using data from Regional Climate Models (RCMs), J. Hydrol., 450, 82-92, 2012

Hao, Z. and AghaKouchak, A.: Multivariate Standardized Drought Index: A parametric multi-index model, Adv. Water Resour., 57, 12-18, 2013.

Heim, R. R.: A Review of Twentieth-Century Drought Indices Used in the United States, B. Am. Meteorol. Soc., 83, 1149-1165, 2002.

Jain, S. K., Keshri, R., Goswami, A., and Sarkar, A.: Application of meteorological and vegetation indices for evaluation of drought impact: a case study for Rajasthan, India, Nat. Hazards., 54, 643656, doi:10.1007/s11069-009-9493-x, 2010.

Keyantash, J. A. and Dracup, J. A.: An aggregate drought index: Assessing drought severity based on fluctuations in the hydrologic cycle and surface water storage, Water Resour. Res., 40, W09304, doi:10.1029/2003WR002610, 2004.

Li, Q., Li, P., Li, H., and Yu, M.: Drought assessment using a multivariate drought index in the Luanhe River basin of Northern China, Stoch. Environ. Res. Risk Assess., 1-12, doi10.1007/s00477-014-0982-4, 2015.

Li, Y., Zheng, X., Lu, F., and Ma, J.: Analysis of Drought Evolvement Characteristics Based on Standardized Precipitation Index in the Huaihe River Basin, International Conference on Modern Hydraulic Engineering, Nanjing, PEOPLES R CHINA, 9-11 March, 28, 434-437, 2012 (Procedia Engineering, 28, 434-437).

McKee, T. B., Doesken, N. J., and Kleist, J.: The relationship of drought frequency and duration to time scales. In: Proceedings of the 8th Conference on Applied Climatology, Vol. 22, B. Am. Meteorol. Soc., 17, 179-183, 1993.

McLeman, R.: Impacts of population change on vulnerability and the capacity to adapt to climate change and variability: a typology based on lessons from "a hard country", Popul. Environ., 31, 286-316, doi:10.1007/s11111-009-0087-z, 2010.

Mu, Q., Zhao, M., Kimball, J. S., McDowell, N. G., and Running, S. W.: A remotely sensed global terrestrial Drought Severity Index, B. Am. Meteorol. Soc., 94, 83-98, 2013.
Qian, W, Shan, X., and Zhu, Y.: Ranking Regional Drought Events in China for 1960-2009, Adv. Atmos. Sci., 28, 310-321, doi:10.1007/s00376-009-9239-4, 2011.

Rajsekhar, D., Singh, V. P., and Mishra, A. K.: Multivariate drought index: An information theory based approach for integrated drought assessment, J. Hydrol., 526, 164-182, doi:10.1016/j.jhydrol.2014.11.031, 2014.

Sohrabiz, M. M., Ryu, J. H., Abatzoglou, J., and Tracy, J.: Climate extreme and its linkage to regional drought over Idaho, USA, Nat. Hazards., 65, 653-681, doi:10.1007/s11069-012-0384-1, 2013.

Svoboda, M. D., Hayes, M., and Heim, R. R.: The Drought Monitor, B. Am. Meteorol. Soc., 83, 1181-1190, 2002.

Todisco, F., Mannocchi, F., and Vergni, L.: Severity-durationfrequency curves in the mitigation of drought impact: an agricultural case study, Nat. Hazards., 65, 1863-1881, doi:10.1007/s11069-012-0446-4, 2013.

Wang, L., Wen, H., Yang, C., Cheng, B., Li, Q., Shi, Z., and Li, P.: Comparison of three drought Indices in Beijing area, Water Resour. Power, 30, 5-7, 2012 (in Chinese).

Wilhite, D. A.: Drought as a natural hazard: Concepts and definitions, in: Drought: A Global Assessment, edited by: Wilhite, D. A., Routledge, New York, 3-18, 2000.

Wells, N., Goddard, S., and Hayes, M. J.: A self-calibrating Palmer Drought Severity Index, J. Climate, 17, 2335-2351, 2004.

Yu, M., Li, Q., Hayes, M. J., Svoboda, M. D., and Heim, R. R.: Are droughts becoming more frequent or severe in China based on the standardized precipitation evapotranspiration index: 19512010?, Int. J. Climatol., 34, 545-558, doi:10.1002/joc.3701, 2014.

Zhang, A. and Jia, G.: Monitoring meteological drought in semiarid regions using multi-sensor microwave remote sensing data, Remote. Sens. Environ., 134, 12-23, 2013.

Zhao, R.: The Xinanjiang model applied in China, J. Hydrol., 135, 371-381, 1992. 